\title{
Overview and Status of Commissioning of the Wendelstein 7-X Magnet Power Supplies
}

\author{
Thomas Rummel, Thomas Moennich, Frank Fuellenbach \\ Max Planck Institute for Plasma Physics \\ Greifswald, Germany \\ thomas.rummel@ipp.mpg.de \\ Tom Murray \\ Applied Power Systems, Inc. \\ Hicksville, NY, U.S.A.
}

July 2015

\begin{abstract}
There are three main magnet systems in Wendelstein 7-X (W7-X), comprising in total 85 coils arranged in 22 independent circuits fed by steady state power supplies. The superconducting coil system creates the main magnetic field and consists of 70 coils, grouped in seven electrical circuits with ten coils each with an inductance of about one Henry. Each circuit is fed by one power supply with a maximum current of $20 \mathrm{kA}$ and a maximum voltage of $+/-30 \mathrm{~V}$. The second coil system is the so-called trim coil system, intended for enhanced experimental flexibility and error field corrections. It consists of five independently powered copper coils which are placed on the outer side of the cryostat. They will be operated with currents of up to $1.95 \mathrm{kA}$. The full scale ratings of a power supply are + / 2200 $\mathrm{A}(\mathrm{dc})$ and +/-230 V(dc). The third magnet system is the divertor control coil system. The ten normal conducting copper coils are situated inside the plasma vessel behind the divertor targets and are arranged in ten independent circuits. The current rating of one power supply is a DC current up to +/-2500 A, which can be modulated by an AC current of up to 625 A with frequencies up to $20 \mathrm{~Hz}$. The commissioning of all systems was made first by using dummy loads, and finally with the installed coils in W7-X. The final commissioning has been running since November 2014 and will be completed in summer 2015.
\end{abstract}

Keywords—Wendelstein 7-X; power supplies; superconducting magnets

\section{INTRODUCTION}

The stellarator fusion experimental device Wendelstein 7-X (W7-X) is presently under commissioning the Max-Planck-Institute for Plasma Physics in Greifswald, Germany. The Basic machine has an outer diameter of 16 meters, a height of about 6 meters and a weight of about 725 tons. The plasma vacuum vessel has a volume of 30 $\mathrm{m}^{3}$, a major radius of 5.5 meters and a minor radius of 0.5 meters. The maximum magnetic flux on the plasma axis will be $3 \mathrm{~T}$. The commissioning of the W7-X is divided into 5 major steps: vacuum tests of the cryostat, cryogenic tests of the cryostat, normal conducting coil systems tests, vacuum tests of the plasma vessel, superconducting magnet coil systems tests, and preparation for the first plasma [1].

\section{MAGnet Systems In Wendelstein 7-X}

\section{A. Superconducting magnets}

The superconducting magnet system of Wendelstein 7-X (W7-X) consists of 50 three-dimensional, so called „non-planar” coils to create the main magnetic field. Five differently shaped coil types (NPC1,..., NPC5) are necessary. The non-planar coils have dimensions of about $3.5 \times 2.5 \times 1.5$ meters and a weight of about 5.5 tons per coil. In addition there are 20 flat coils, so-called "planar" coils, which are nearly circular with diameters of up to 4 meters and a weight of about three tons. Two differently shaped coil types (PLCA and PLCB) will be used.

The ten coils of the same type are connected in series to form an electrical circuit. Consequently there are five circuits consisting of non-planar coils and two circuits consisting of planar coils. A non-planar coil circuit represents a load of about 1 Henry, whereas a planar coil circuit has an inductance of about 0.4 Henry. The 
magnetic coupling between the coil circuits depends on the location the coils in the toroidal arrangement and its distance to the circuits containing other coil types. The coupling factor $\mathrm{k}$, which is defined as

$$
\mathrm{k}=\mathrm{M} /\left((\mathrm{L} 1 * \mathrm{~L} 2)^{1 / 2}\right)
$$

$\mathrm{M}=$ mutual inductance between circuits 1 and 2; L1=inductance of circuit $1 ; \mathrm{L} 2=$ inductance of circuit 2

varies in $\mathrm{W} 7-\mathrm{X}$ between 0.01 and 0.3 .

\section{B. Trim coils}

The second coil system is the so-called trim coil system, intended for enhanced experimental flexibility and error field corrections. It consists of five water cooled copper coils of two different types A and B, placed on the outer side of the cryostat. Four coils (type A) are identical in size and shape. They have overall dimensions of $3.5 \times 3.3$ meters with 48 turns and will be operated with currents of up to $1.8 \mathrm{kA}$. They represent a load of $19 \mathrm{mH}$ and $53 \mathrm{~m} \Omega$. The trim coil type B is smaller (2.8x2.2 meters) than the type A coils, but has more turns (72) and will be operated at higher currents (up to $1.95 \mathrm{kA}$ ). Its electrical parameters are $26 \mathrm{mH}$ and $29 \mathrm{~m} \Omega$.

\section{Control coils}

The third main magnet system in W7-X is the control coil system. Ten normal conducting copper coils are situated inside the plasma vessel behind the divertor targets. One coil has dimensions of $2.0 \times 0.4$ meters, a weight of about $70 \mathrm{~kg}$ and an inductance of $188 \mu \mathrm{H}$. Each coil consists of 8 turns of a rectangular copper profile with integrated circular cooling water channel. Like all the other coils, the control coils are designed for steady state operation of up to 30 minutes.

\section{MAGNET POWER SUPPLIES}

\section{A. Superconducting coil power supplies}

The standard magnetic configuration of W7-X is formed by the 50 non-planar superconducting coils operated at the same current in all coils. The 20 additional planar superconducting coils allow, together with different currents in the non planar coil circuits, the modification of plasma confinement parameters like shear or the rotational transformation. In addition, it will allow the plasma to be shifted further inwards or outwards to position it properly with respect to the plasma facing components. This flexibility is a key element of the Wendelstein 7-X experimental device. But it results in more demanding requirements for the power supplies. Instead of one common power supply for the standard magnetic field, now seven independently adjustable power supplies are necessary.

One very special issue with respect to the power supply is the decision to place the power supplies inside the experimental hall underneath the W7-X. The motivation was to reduce the power loss in the bus bars from the power supplies to the W7-X device. Presently the power supplies are inside the experimental hall, but in a lower level at a distance of about 10 meters from the W7-X cryostat. There are two major consequences associated with locating the power supplies close to the W7-X device. The first of which has to do with the lack of available space. One power supply including grid transformers, rectifier, load switches, interphase reactors and current transducers had to be squeezed in a volume of $4 \times 3.5 \times 2.5$ meters $(\mathrm{W} \times \mathrm{DxH})$. The height being limited to 2.5 meters was an especially difficult dimension. It resulted in some compromises in the design of the transformer with respect to power losses.

The second severe consequence for the power supplies is the presence of the stray magnetic field in the power supply areas. Calculations of the expected magnetic induction indicate that the power supplies will be subjected to stray field of up to $10 \mathrm{mT}$. This issue had to be considered early in the design phase, e.g. some types of magnetic relays had to be excluded. In addition several test campaigns were performed to check the proper behavior of components in the magnetic field, like electronic boards, current and voltage transducers, control racks, load switches, and the d.c. circuit breakers of the magnet safety system.

The maximum current during plasma operation will be $18.2 \mathrm{kA}$. To have a sufficient margin the design requirement for all power supplies was $20 \mathrm{kA}$ steady state. Steady state is defined as five days of continuous operation. The requirement for controlled ramp-up and ramp-down for plasma parameter studies led to the decision of a two-quadrant converter. Each coil circuit will be fed by one power supply with a maximum current of $20 \mathrm{kA}$ and a maximum voltage of $+/-30 \mathrm{~V}$. The ramp rate can be varied from $5 \mathrm{~A} / \mathrm{s}$ to $30 \mathrm{~A} / \mathrm{s}$. The power supply is supplied from the $20 \mathrm{kV}$ grid by two transformers each rated at $490 \mathrm{kVA}$, one of the delta/wye+wye and the other of the wye/wye+wye type. The four secondary windings of the two transformers are shifted by 30 degree (el.) from each other. They supply four mid point connections (M3) with one thyristor per branch. The connection between the four M3 systems is made by interphase reactors. The dc voltage ripple at the output is attenuated by a passive filter to 17 volts (pp) maximum [2]. 
One of the essential aspects of operating superconducting magnets is the protection against damages due to quenches. Therefore the protection system is an integral part of the power supply system. In case of a quench or another severe failure, the stored energy in the magnets has to be removed from the coil very quickly. That means the protection system separates the power supply from the coil and brings the coil current into a circuit containing the dump resistor. The total system consists of a combination of electronically and mechanically actuated switches and breakers, an explosive fuse and the dump resistor, made of Nickel. The protection system is able to deenergize the coil circuit within 12 seconds, whereas the rectifier would need 12 minutes. Tests of the discharge scenarios are also part of the commissioning.

TABLE I PARAMETERS OF A POWER SUPPLY FOR THE SUPERCONDUCTING COILS [2]

\begin{tabular}{|c|c|c|}
\hline Designation & Value & Unit \\
\hline Input voltage & 20 & $\mathrm{kV}$ \\
\hline Output voltage & $0 \ldots \pm 30$ & $\mathrm{~V}$ \\
\hline Output current & $0 \ldots 20$ & $\mathrm{kA}$ \\
\hline Precision of the current & \pm 0.2 & $\%$ \\
\hline Ripple of the current & $<10$ & $\mathrm{~mA}(\mathrm{pp})$ \\
\hline Ripple of the voltage & 17 & $\mathrm{~V}(\mathrm{pp})$ \\
\hline Max. power loss & 80 & $\mathrm{~kW}$ \\
\hline Dimensions (W $\times$ D $\times \mathrm{H})$ & $4 \times 3.1 \times 2.3$ & $\mathrm{~m}$ \\
\hline Weight & 15.5 & tons \\
\hline
\end{tabular}

\section{B. Trim coil power supplies}

Despite of the slightly different load conditions caused by the two coil types, five equal power supplies will be used. Each power supply is connected to the $400 \mathrm{~V}$ three phase grid and consists of an input transformer (delta/delta+delta typ) of $450 \mathrm{kVA}$ which has at its secondary sides two three phase systems at $192 \mathrm{~V}$ each, shifted by 30 degrees (electrically) from each other, followed by two diode six pulse diode bridges creating a DC bus of $260 \mathrm{~V}$, buffered with capacitors of $268 \mathrm{mF}$. The power conversion is being made by H-bridges using InsulatedGate-Bipolar-Transistors (IGBT) with internal freewheeling diode. In total $12 \mathrm{H}$-bridges are connected in parallel. The output parameters of each power supply are $+/-2200 \mathrm{~A}$ and $+/-230 \mathrm{~V}$. The input transformer, the rectifier diodes and the chill plates of the H-bridges are directly water cooled [3].

Coils and power supplies are an in-kind contribution from the U.S. labs PPPL and ORNL. The power supplies were designed and manufactured by Applied Power Systems, Inc. of Hicksville, NY.

TABLE II. PARAMETERS OF A TRIM COIL POWER SUPPLY [3]

\begin{tabular}{|c|c|}
\hline Designation & Type A and B Coil \\
\hline Maximum output voltage & $\pm 230 \mathrm{~V}$ \\
\hline Maximum current & $\pm 2200 \mathrm{~A}$ \\
\hline Current control range & $-2.2 \mathrm{kA} . .+2.2 \mathrm{kA}$ \\
\hline Maximum ramp rate & $2200 \mathrm{~A} / \mathrm{s}$ \\
\hline Maximum power loss & $20 \mathrm{~kW}$ \\
\hline Current control accuracy & $\pm 10 \mathrm{~A}$ \\
\hline Long term stability of current $(30 \mathrm{~min})$ & $\pm 10 \mathrm{~A}$ \\
\hline Residual ripple of current & $5 \mathrm{App}$ \\
\hline Dimensions (W x D x H) & $1.4 \times 1.4 \times 2.1[\mathrm{~m}]$ \\
\hline Weight & $2600 \mathrm{~kg}$ \\
\hline
\end{tabular}

\section{Control coil power supplies}

The ten normal conducting control coils are situated inside the plasma vessel and will be used 
- $\quad$ a) to correct symmetry-breaking error fields and to eliminate the corresponding islands, and

- $\quad$ b) to sweep the plasma deposition area across the target plates avoiding excessive temperatures.

The power supplies have to provide a variable bi-directional steady state field to fulfill requirement a), and in addition an alternating field to fulfill requirement $b$ ).

The power supplies therefore have to provide a direct bi-directional current with high accuracy, which can be modulated by an alternating current with different frequencies.

The complete system contains ten power supplies, a supply distribution module, a cooling module and a superordinated control unit. Connection to the control coils is made by $4 \times 630 \mathrm{~mm} 2$ flexible power cables. Low current density in the power cables was chosen to reduce voltage drop and power losses. The power supplies are fed from the $400 \mathrm{~V}$ grid with a maximum rated power of $70 \mathrm{kVA}$ per power supply. The 12 pulse system is generated in the same manner as for the power supplies for the superconducting coils. Each of the 12 branches coming from the transformers is connected to a rectifier diode, forming a DC bus of $60 \mathrm{~V}$. A capacitor of $2.4 \mathrm{~F}$ stabilizes the bus and has to dump the stored energy in the control coil in case of an emergency shutdown of the system. The inverter stage is build up by an H-bridge converter with 12 MOSFET transistors in parallel in each branch. A filter capacitor and inductance are connected to the output of the inverter stage to assure the low ripple requirements for the current and voltage. The transformers are cooled by water-air heat exchangers. The chill plates of the inverter MOSFET transistors and the rectifier diodes are directly water cooled to avoid excessive heating inside the power supplies. The output current of this power supply is a d.c. current of up to $+/-2500 \mathrm{~A}$, which can be modulated by an a.c. current of up to $625 \mathrm{~A}$ with frequencies up to $20 \mathrm{~Hz}$ [4].

The control coil power supplies are installed in the experimental hall underneath of the W7-X device. The consequences are similar the situation of the superconducting coil power supplies. The space is very restricted and the power supplies including the local controls have to operate under the influence of the stray magnetic field.

TABLE III. PARAMETERS OF A CONTROL COIL POWER SUPPLY
\begin{tabular}{|c|c|c|}
\hline Designation & Value & Unit \\
\hline DC current & $0 \ldots \pm 2500$ & $\mathrm{~A}$ \\
\hline AC current & $0 \ldots 625$ & $\mathrm{~A}$ \\
\hline Max. Peak current & 3125 & $\mathrm{~A}$ \\
\hline Frequency of the AC current & $0 \ldots 20$ & $\mathrm{~Hz}$ \\
\hline Ripple of the DC current & $<1$ & $\mathrm{~A}$ \\
\hline Effective voltage & 30 & $\mathrm{~V}$ \\
\hline Dimensions (W x D $\mathrm{H}$ H) & $1.1 \times 1.1 \times 2.2$ & $\mathrm{~m}$ \\
\hline Weight & 1000 & $\mathrm{~kg}$ \\
\hline
\end{tabular}

\section{STATUS OF THE COMMISSIONING}

The commissioning comprises all tests after the fabrication with the final aim to operate the power supplies together with its dedicated and finally installed load. In general, the following main steps were performed:

a) acceptance tests after manufacture

b) tests at the customer using dummy loads

c) integral tests at the customer using the dedicated load.

\section{A. Superconducting coil power supplies}

In contradiction to the above described strategy, tests at the manufacturer's site were not possible due to the unavailability of the necessary electrical power. In addition the final assembly took place at the customer and not at the manufacturer's site. Therefore the acceptance test was performed at the customer's site. A superconducting coil represents a special load, characterized by a very low ohmic resistance and at the same time by a relatively high inductance. To cope with these special conditions the following test strategy was chosen. In a first step the power supplies were tested in short circuit. This represents a very low ohmic load of few micro Ohms, and simulates therefore the first parameter of a superconducting load. The inductance was below $10 \mu \mathrm{H}$. The tests 
were performed up to the maximum current. In a second step a dummy load of $3.1 \mathrm{mH}$ and $1.5 \mathrm{~m} \Omega$ was used, which is still a factor of 300 away from the final inductive load but on the other hand a factor of 300 more relevant than a short circuit. The tests were performed also up to the maximum current. Special attention was given to the parameters: accuracy of the current, load line, power loss, voltage and current ripple. Also a temperature rise test over 24 hours was performed to show, that the temperature of the main components (transformers, thyristor chill plates, interphase reactors) did not exceed the maximum design temperatures.

Due to the inductive coupling between the electrical circuits in W7-X as described in chapter I, tests with a special dummy load system which simulates the magnetic coupling were also performed. The dummy load system consisting of seven water cooled copper coils (one per power supply) was built-up in the W7-X experiment hall (Fig. 1). Each coil has an inductance of $1 \mathrm{mH}$ and a resistance of $1 \mathrm{~m} \Omega$. This test load has created a certain inductive load which is an important prerequisite to check the controller's behavior. The more important issue of the test load system was the simulation of the magnetic coupling between the seven circuits which should be comparable to the situation in W7-X. The magnetic coupling between the two test coils next to each other should be as similar as possible compared to the W7-X. This was achieved for the coils, simulating the non planar coil groups. The coupling factor in $\mathrm{W} 7-\mathrm{X}$ is between 0.27 and 0.32 , in the tests arrangement a factor of 0.31 was used. The compromise is on the other hand that the coupling to the other coils is different to the W7-X conditions. This is obvious, because in $\mathrm{W} 7-\mathrm{X}$ the coils forming a toroidal arrangement compared to the straight cylindrical configuration of the test load system.

The coupling factors were created by the distance between the individual dummy coils. For proper adjustment thin layers of pressed wooden plates were used. So the coupling factor could be adjusted properly, at the same time a good mechanical support between the coil bodies was reached (Fig. 1).

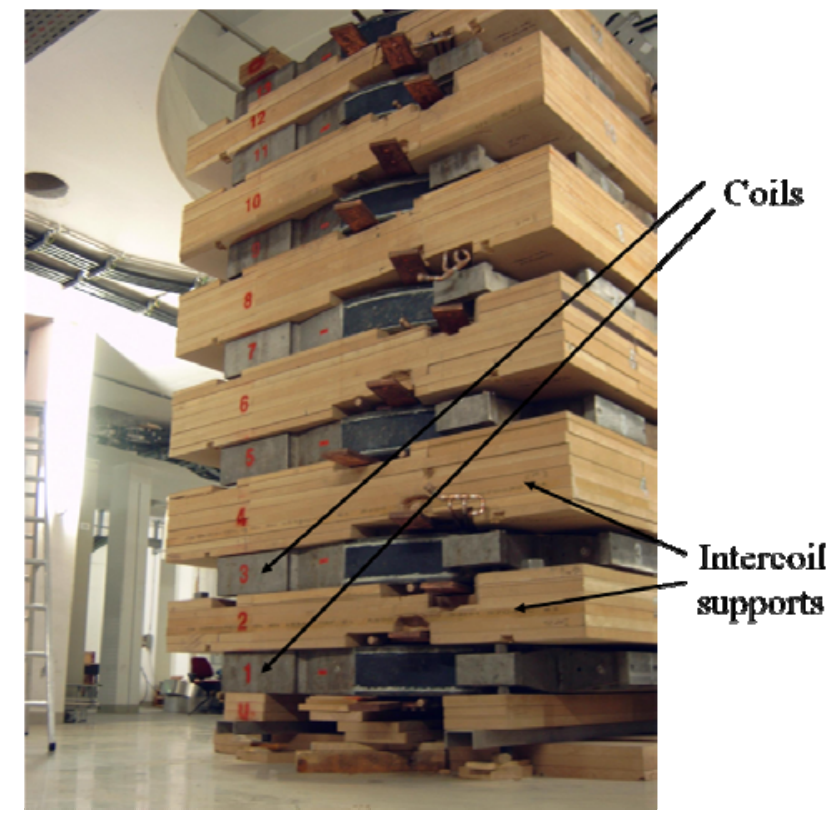

Fig. 1. Test load to simulate the inductive coupling for the combined test of the seven power supplies.

In W7-X there are eight predefined magnetic field configurations at three different absolute induction levels, taking into account that $\mathrm{W} 7-\mathrm{X}$ can work at $3 \mathrm{~T}, 2.5 \mathrm{~T}$ and $1.25 \mathrm{~T}$ on the plasma axis. This gave in total 24 magnetic configurations to be checked in the test program.

During the tests, special attention was given to the accuracy of the current under the condition that all seven power supplies are working at the same time to a magnetically coupled load. Other test were performed to check the long term stability over a period of 8 hours, the reaction after (simulated) failures and the behavior during ramp-up and ramp-down. This test is a consequence from the magnetic coupling between the coil circuits and the required experimental flexibility. During ramp-up the relation between the seven currents has to be in the same relation than in the steady state-phase. As an example the factor between the currents in coil group one and five is 1.35. The requirement is to have the same factor also during ramp up and ramp-down. This requirement is important to have a similar mechanical load distribution between the coil groups in W7-X. Also the magnet safety systems were tested by initiating fast discharges. The main circuit is opened by dc circuit breakers and the current 
is transferred to the dump resistor branch. Aim of the tests was to check the switch-off behavior of the breakers against an inductive load and the temperature increase in the dump resistor.

All tests were performed successfully over a period of several weeks and gave the confidence for the integral commissioning using the superconducting loads.

The integral commissioning of the power supplies together with the superconducting coils started at the end of April 2015. Two days per week are dedicated for the tests, the remaining four days of the working week are still reserved for assembly activities of diagnostics, cable trays, pipes and so on.

The total electrical circuit comprises the power supply, the room temperature bus bars, the flexible copper breeds at the transition to the two HTS current leads [5], [6], 11 superconducting bus bars which connect coils with each other and with the current leads by the means of special low ohmic joints. Superconducting bus bars and joints were never tested before under cryogenic conditions and with electrical current, therefore the integral commissioning has to show both, the proper operation of the power supplies under the new load, and the proper superconducting behavior of the whole superconducting circuit.

The strategy for the integral commissioning is divided in two main steps:

- Test of the seven coil groups one by one up to the required current for the first operation phase (OP1.1) or, if lower, up to the allowed current for individual operation,

- Test of the seven coil groups together (combined tests) up to the current foreseen for OP1.1.

The tests of the individual coil groups were done in the following order:

1. Adjustment of the quench detection system by increasing the current of up to $500 \mathrm{~A}$ with ramp rates from $5 \mathrm{~A} / \mathrm{s}$ to $30 \mathrm{~A} / \mathrm{s}$;

2. Ramp-up to $2 \mathrm{kA}$, followed by a steady state phase of one hour (check of the mechanical and thermo hydraulically behavior), ramp-down to zero (ramp rates $30 \mathrm{~A} / \mathrm{s}$ );

3. Ramp-up to $2 \mathrm{kA}$, followed by a steady state phase of ten minutes (check of the mechanical and thermo hydraulically behavior), ending with a slow emergency discharge;

4. Ramp-up to $2 \mathrm{kA}$, followed by a steady state phase of ten minutes (check of the mechanical and thermo hydraulically behavior), ending with a fast emergency discharge;

5. Ramp-up to $2 \mathrm{kA}$, followed by a steady state phase of ten minutes (check of the mechanical and thermo hydraulically behavior), ramp-down to zero (ramp rates $30 \mathrm{~A} / \mathrm{s}$ ) to check the proper behavior after the fast discharge;

6. Repetition of 2.-5. with currents of $5 \mathrm{kA}$ (planar coils), and $6 \mathrm{kA}$ (non planar coils) and $10 \mathrm{kA}$ (non planar coils type 1 and 5) or $12.8 \mathrm{kA}$ (non planar coils types 2, 3, and 4).

Fig. 2 shows the test sequence of the non planar coil circuit 1 in May 2015.

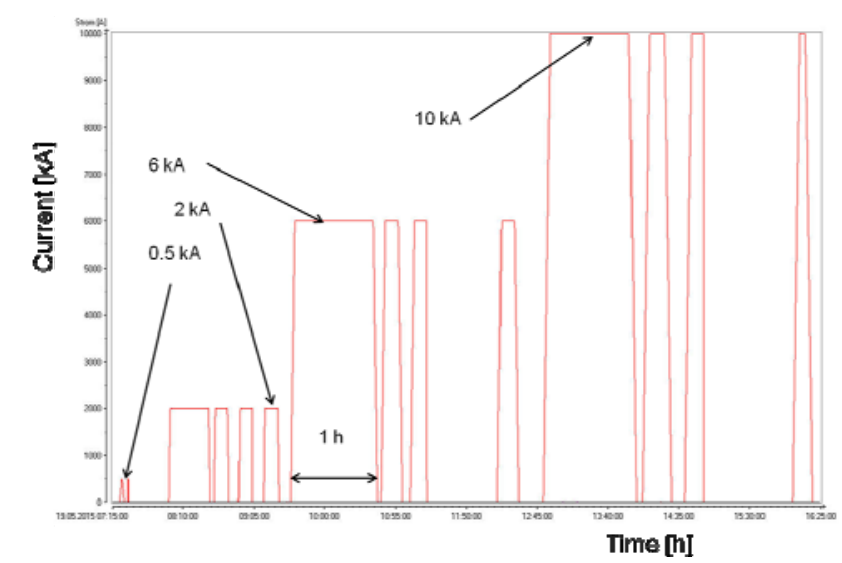

Fig. 2. Current vs time during the commissioning of a non planar coil circuit showing the steps described above. 
The results are all positive; the several levels of the current were reached without problems, no quenches occurred neither during ramp-up, steady state or ramp-down, nor during slow or fast discharge. The power supplies have been working without problems; the accuracy and the long term stability during pulses of up to 4 hours are well within the specification. The ramp rates are stable and linear, too. Slow and fast emergency discharges of the coils were performed in the expected manner. The contact elements in the dc circuit breakers of the magnet protection system did not show undue degradation. The temperature increase in the dump resistors was lower than calculated. The tests were successfully completed for all coil circuits in June 2015.

The tests of the seven coils circuits together follow the same sequence than the individual coil circuit tests. In addition a long pulse test of about 4 hours at the highest current level will demonstrate the necessary long term stability of the power supply system. The combined tests have been started end of June 2015, reaching the operation current of $12.8 \mathrm{kA}$ of the Wendelstein 7-X first plasma phase on the $6^{\text {th }}$ of July 2015 for the first time. Later in July 2015 the current was increased to $13.4 \mathrm{kA}$ to have more flexibility with respect to the plasma operation program. Operation at the full current of $18.2 \mathrm{kA}$ is scheduled for 2019 when the high power long pulse plasma tests of W7-X will be performed.

\section{B. Trim coil power supplies}

Among other test during the fabrication, tests at full current were performed on the completed power supply. In order to test the output parameters, a $100 \mu \mathrm{H}, 170 \mu \Omega$ dummy load was placed across the output. Tests completed at the manufacturer included the operation at full current to check the accuracy and the ripple of the output current. The tests were repeated after the installation of the power supplies at the customer with a dummy load of $6.8 \mathrm{mH}, 40 \mathrm{~m} \Omega$, to check that the transportation over a distance of several thousand kilometers (or miles) and the installation did not create unacceptable deviations. Later a dedicated test program for each power supply to check all specified values was set-up and executed in June 2014. The following points have been tested: accuracy and stability of the current, voltage and current ripple, power consumption, temperature evolution during long pulse tests (heat run), ramp rates of up to $2.2 \mathrm{kA} / \mathrm{s}$ of the current without and with zero crossing, reaction to simulated internal and external failures.

In general all tests were successfully completed, a few minor adjustments of the controller were part of the tests. Finally all power supplies work as expected.

The integral commissioning of the power supplies together with the trim coils took place in November 2014 over a period of two weeks. It was the first time that the power supplies were operated under the final load conditions and that the trim coils were operated with any current. Therefore an extensive test program was executed, starting at relatively small currents of $100 \mathrm{~A}$ and slow ramp rates of $50 \mathrm{~A} / \mathrm{s}$. Step by step the current and the ramp rates were increased up to $2 / 3$ of the maximum current and up to the maximum ramp rate of $2.2 \mathrm{kA} / \mathrm{s}$, respectively. Zero crossing of the current was also performed at different ramp rates. The limitation of the maximum test current to $2 / 3$ of the maximum design current was solely caused by the still running assembly activities of the periphery and the diagnostics of the W7-X device. Especially the still present ferromagnetic scaffolding around the W7-X device would have been loaded with too high forces due to the field of the coils.

During heat runs it was confirmed that the coils reach the equilibrium very fast. It took about 5 minutes to reach the final temperature. Also the temperature distribution within the coil is very uniform. The temperature differences between the pancakes are in the range of $1.5 \mathrm{~K}$ which is well below the required $2.5 \mathrm{~K}$.

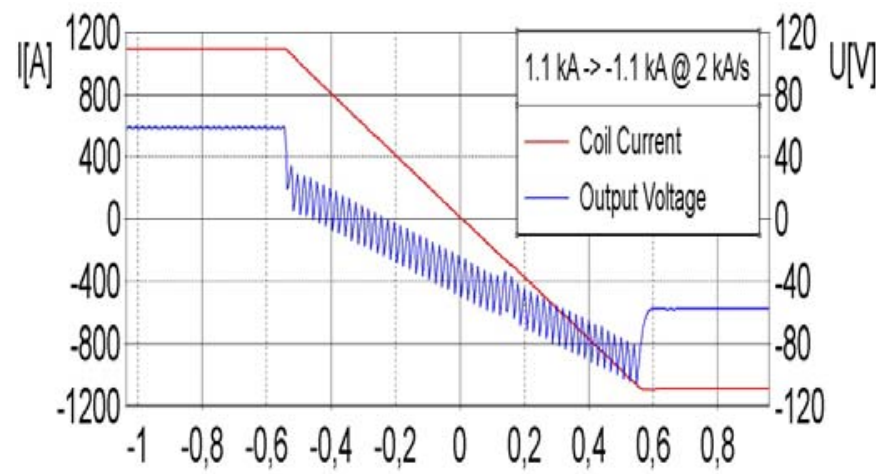

Fig. 3. Current ramp from $1100 \mathrm{~A}$ to $-1100 \mathrm{~A}$ (ramp rate $2000 \mathrm{~A} / \mathrm{s})$. 
Finally the combined operation of all five power supplies was tested. Combined operation means that the central control of the trim coil system co-ordinates and synchronizes the operation, e.g. the start of the current, the execution of current ramps, the reaction to internal or external commands or failure messages. Fig. 3 shows a transition from +1100 A to -1100 A with a ramp rate of $2000 \mathrm{~A} / \mathrm{s}$ and the related output voltage of the power supply. The transition of the current runs as expected. The voltage ripple during the ramp is about $20 \mathrm{~V}$ which is uncritical.

The results of all the tests are all within the specifications, coils and power supplies behaved as expected. The trim coil system is ready for the plasma operation of W7-X.

\section{Control coil power supplies}

The factory tests at the manufacturer were performed with a dummy load of $180 \mu \mathrm{H}$ and $6 \mathrm{~m} \Omega$. Parameters like current and voltage were tested successfully, also the reaction with respect to failures was simulated. A important test was the operation under the influence of a static magnetic field. Two large copper coils with diameters of 2 meters were placed on the left and on the right of the power supply cabinet and supplied with a dc current to create an external field. Then the power supply was operated. It turned out that the power supply could not be operated properly under the influence of a field of $50 \mathrm{mT}$, as requested in the specification. But the disturbances started above $40 \mathrm{mT}$, therefore external shielding provided by an additional steel cabinet around the original one solved the problem.

The test at the customer's site took place using a dummy load of $188 \mu \mathrm{H}$ and $3.9 \mathrm{~m} \Omega$, which are nearly the parameters of the control coils. Also during these tests all main parameters were successfully tested, including ac and dc output current, current and voltage ripple, and temperature evolution during a heat run [3]. Later the tests were repeated successfully using one control coil in a test rig.

The integral commissioning of the completely installed system of coils and power supplies and auxiliary systems has been started in February 2015. It runs with lower priority, because the control coils will not be used during the first operation phase of W7-X. The power supplies shall deliver ac and dc currents, therefore a sophisticated test program was executed. First several levels of the dc currents were checked in the full range from $+2500 \mathrm{~A}$ to $-2500 \mathrm{~A}$, then the sequence was repeated with ac output currents from $+625 \mathrm{~A}$ to $-625 \mathrm{~A}$ with frequencies between 1 and $20 \mathrm{~Hz}$. The next step comprised several combinations of the dc and ac current, with or without zero crossing of the current.

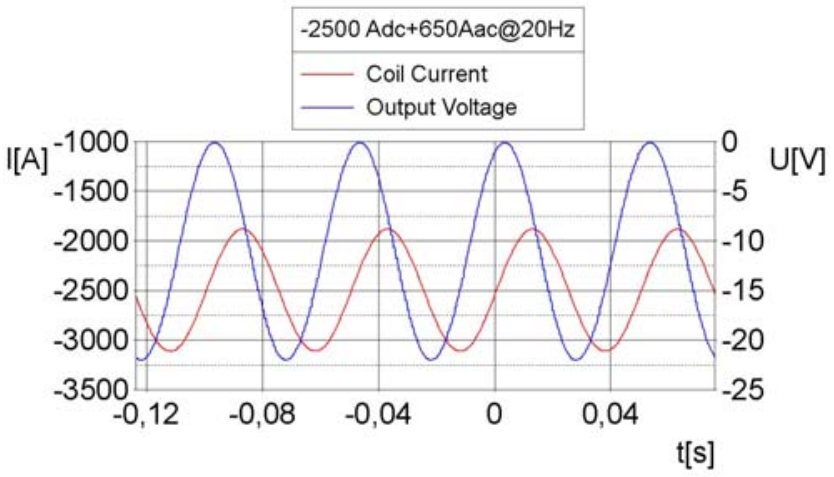

Fig. 4. Output current and output voltage of a power supply (superposition of a DC current of $-2500 \mathrm{~A}$ and an AC current of $+625 \mathrm{~A}$ at 20 $\mathrm{Hz})$.

Fig. 4 shows one example of the superposition of the DC and the AC part of the current.

As per end of June 2015, eight power supplies have been finally commissioned. The results of all the tests are within the specifications, coils and power supplies behaved as expected.

\section{SUMMARY}

The power supplies of the three main magnet systems in Wendelstein 7-X have been installed completely and were tested successfully using dummy loads during the last years. The integral commissioning of power supplies for the superconducting coils and of the control coils is well under way. The integral commissioning of the trim coil systems was already successfully finished. 


\section{ACKNOWLEDGMENT}

This work has been carried out within the framework of the EUROfusion Consortium and has received funding from the Euratom research and training program 2014-2018 under grant agreement No 633053. The views and opinions expressed herein do not necessarily reflect those of the European Commission.

The collaboration in the field of the trim coils and power supplies between IPP and the US associations Princeton Plasma Physics Laboratory and Oak Ridge National Laboratory as well as the funding provided by the U.S. Department of Energy is gratefully acknowledged.

The authors thank also the involved colleagues and companies for their work and co-operation in all the W7-X magnet power supply systems.

\section{REFERENCES}

[1] H.-S. Bosch, R. Brakel, M. Gasparotto, H. Grote, D. A. Hartmann, R. Herrmann, M. Nagel, D. Naujoks, M. Otte, K. Riße, Th. Rummel, and A. Werner, "Transition from Construction to Operation Phase of the Wendelstein 7-X Stellarator", IEEE Trans. Plasma Science, Vol. 42, pp. 432-438, March 2014.

[2] Th. Rummel, F. Füllenbach, and Th. Mönnich, "Power supplies for the WENDELSTEIN 7-X stellarator," Fusion Engineering and Design, Volumes 66-68, pp. 1115-1118, September 2003.

[3] Th. Rummel, K. Riße, F. Füllenbach, M. Köppen, J. Kißlinger, T. Brown, R. Hatcher, S. Langish, M. Mardenfeld, and H. Neilson, „The Wendelstein 7-X Trim Coil System,“ IEEE Transactions on Applied Superconductivity, Vol. 24, No. 3, p. 4200904, June 2014.

[4] F. Füllenbach, Th. Rummel, S. Pingel, H. Laqua, I. Müller, and E. Jauregi, "Final test of the W7-X control coils power supply and its integration into the overall control environment," Fusion Engineering and Design, Volume 82, Issues 5-14, pp. 1391-1395, October 2007.

[5] W.H. Fietz, R. Heller, A. Kienzler, and R. Lietzow, "High Temperature Superconductor Current Leads for WENDELSTEIN 7-X and JT-60SA,” IEEE Trans. on Appl. Supercond. vol 19, no 3 (2009), pp. 2202-2205.

[6] Reinhard Heller, Klaus-Peter Buscher, Sandra Drotziger, Walter H. Fietz, Andreas Kienzler, Ralph Lietzow, Thomas Mönnich, Thomas Richter, Thomas Rummel, Elisabeth Urbach, „Status of series production and test of the HTS current leads for Wendelstein 7-X," Fusion Engineering and Design, Volume 88, Issues 9-10, pp. 1482-1485, October 2013. 